\title{
A Study of Dynamic Forecast on Port Container Handling Capacity
}

\author{
Zhan-Qing Feng ${ }^{*} \cdot$ Su-Ho Lee* \\ *PhD Course, Advanced School, Korea Maritime University \\ **Professor, Korea Maritime University \\ 항만 컨테이너 처리능력의 동태적 예측에 관한 연구 \\ 馮湛青*·이 수 호**. \\ *한국해양대학교 대학원, **한국해양대학교 교수
}

요 약 : 컨테이너 처리량 $(\mathrm{CHC})$ 은 항만의 능력을 나타내는 중요한 지표다. 그러나 중국항만의 컨테이너 처리능력에 대한 연구는 부족하며, 연구결과 또한 예측치와 실제치와의 차이가 크다. 이는 컨테이너처리량이 다양한 경제적인 측면을 내포하고 있고 예측모델의 선택이 매우 어렵 다는데 기인한다. 대체로 지금까지 사용되어왔던 회거분석, 신경망분석 등은 과거행태모델을 뱃어나지 못하고 있어 경재체제나 항만물동량의 동태적변화에 대한 고려가 결여되어 있다. 따라서 본 논문에서는 동태적 보정인과모델을 사용한 동태적 예측법을 사용해 보았고 그 결과 보다 신뢰성이 높고 현실성이 있는 연구결과롤 도출할 수 있었다

핵심용어 : 컨테이너처리능력, 동태적 예측, 신경망, 실효치, 동태적보상치, 자료포괄분석, 국내총생산

Abstract : In view of the great disparity between the previous forecasts of Shanghai port container handling capacity and its real results, we choose a dynamic forecast method by the causality model with dynamic compensation to predict Shanghai port container handling capacity. And we forecast Shanghai port container handling capacity by using this method. We have made a satisfactory achievement, which provides a more reliable and practioal way to forecast container handling capacity.

Key words : container handling capacity, dynamic forecast, neural network, effcftive value, dynamic compensation value, DEA, GDP

\section{Introduction}

China, situated in the west coastline of Pacific Ocean, has been attracting more and more attention from all over the world for its rapid economic growth. The shipping industry, propelled by the high-speed economic growth, also has had a fast development. The great change of economic structure and the adjustment of the industrial structure will further increase the containerization rate of Chinese ports. In fact, the container handling capacity $(\mathrm{CHC})$ has been become an important indicator for the capacity of a port; it is also an important foundation for a city or nation to formulate its port development aim. That is why it is of great significance to have an accurate assessment of $\mathrm{CHC}$.

However, at present there is a deficiency in the forecast of $\mathrm{CHC}$ in Chinese literatures, which consists in the predication figure is less than it actually is.

Take article [1]1) for example, the forecast of $\mathrm{CHC}$ of Shanghai port in 2000 was $3.75 \mathrm{~m}$ TEU, while the actual CHC was over $5.61 \mathrm{~m}$ TEU. Another example in article [2]2) predicates that by the year 2005, the $\mathrm{CHC}$ of Shanghai port can reach only $5.50 \mathrm{~m} \sim 6.00 \mathrm{~m}$ TEU; this is obviously wrong. The mistake arising from it is due to the fact that $\mathrm{CHC}$ itself is a complicated economic system that involves a wide range of aspects.

On the other hand, choice of forecast models is also an essential cause for such a mistake. The current analysis is mostly based on the model of regression analysis, time order analysis or neural network analysis etc. No matter what sort of models they are using, the historical data are invariably employed to establish the past and present systematic behavioral model so as to predicate the future. Such an

* 종신회원, leesh@hanara.kamritime.ac.kr 051)410-4404

** 비회원, fengzhaq@hotmail.com

1) Xu Jianhua, the Comparison of Container Handling capability Between Hong Kong and Shanghai Port, Containerization, Shanghai Maritime University, 1998(3).

2) Tian Zuochen, Shanghai International Shipping Center and Shanghai port Development, Shipping Management, Shanghai Maritime University, 1998 (12). 
A Study of Dynamic Forecast on Port Container Handling Capacity

analysis is only an extension of the past behavioral model, which lacks the consideration of the economic system or lacks the consideration of the dynamic change of $\mathrm{CHC}$.

So, the author of this article employs a dynamic forecasting method to predicate $\mathrm{CHC}$ of a port: First of all, a neural network method is used to achieve a static analysis of the causality of $\mathrm{CHC}$. Then, considering the rapid growth of $\mathrm{CHC}$, a dynamic compensation is be added to the result of the causality forecast so that a dynamic forecast can be achieved to predicate the $\mathrm{CHC}$.

\section{Actualization of the Structural Neural Network Model for $\mathrm{CHC}$}

The Artificial Neural Network (ANN) is characterized as flexible self-adaptability, capability of realizing the implicit expression of non-linear relation, and being permissive of errors. It can deal with the problem of non-complete information. At the same time, no matter what the organizational form of the network, it can always possess a feather of learning, summarizing, and drawing out; in this way, a more fit accuracy can be achieved to apply for forecasting. So in this article, ANN is employed for causality forecast model.

The Structural Neural Network Forecast is in contrast to the Time Neural Network Forecast. The so-called Time Neural Network Forecast, based on the principle of the Neural Network Forecast, is to forecast the input array matrix. It consists of the historical data on a time series, fits the forecasting value and the normal samples, to establish the connection weighted value matrix and threshold value matrix among the input array, implicit array and output array on the temporal neutral network after thousands of fitting to achieve a high accuracy, and to forecast the future index data on the basis of such matrixes.

While the Structural Neural Network alters the practice of input array matrix that fits with the normal sample matrix on the basis of time series, it takes the practice of structural concept to fit with the intrinsic variable index that has a decisive impact on forecast variable and the corresponding input array matrix consisting of forecast variable, to establish the connection weighted value and threshold value among the layers of the Structural Neural Network after arriving at an adequate accuracy, and to forecast the future variable value on the established network.

In this article, the author uses the domestic gross product (GDP) and the foreign import-export volume (FIEV) to predicate the container handling capacity since they are strongest in terms of correlation with $\mathrm{CHC}^{3}$ ). In order to achieve a dynamic effect of forecast, we take into consideration of the last year's CHC, GDP, FIEV and this year's GDP, FIEV, which are formed a vector to forecast this year's CHC.

The above-mentioned training and testing, weighted value aggregate and threshold value aggregate in the Neural Network are established on the base of historical data observation. Such a forecast model reflects the past and present average behavioral model. Thus, even if they are described in a vivid way, they fail to notice the dynamic development over the time span. Actually, for the dynamic economic system, the behavioral model is varying ever and again, and the behavioral model on the forecast series system is likely to differ from the established the forecast model. Such difference might derive from the structure. If the above static result is employed directly to forecast, the outcome will turn out to be a deviation from the actual dynamic economic system. This deficiency derives essentially from the fact that the static forecast model has an insufficient information exploration into the economic system and its historical behavioral variable. In order to remedy such a deficiency, we should from the historical information find out that part which can reflect the dynamic development of the system. In this way, we can forecast the dynamic economic development.

This article, from a view of quantitative analysis for the systemic behavioral model, adopts such a method to compensate the dynamic $\mathrm{CHC}$, which will reflect a more accurate dynamic change of the $\mathrm{CHC}$.

\section{The Dynamic Compensation of the $\mathrm{CHC}$}

\subsection{The Basic Principle of the Dynamic Compensation}

The definite behavioral model of the system can be quantitatively described with the "distance" in its most favorable behavioral model; while the most favorable behavioral model can be described with the Effective Value. The concept effective value is:

The actual production system, which is generally not in its most favorable production state (or most favorable behavioral model), will get a suppositional value of the output variable, on the assumption that the actual production system is in its most favorable state, at the same time keeps the same input scale. Such a suppositional value is called the effective

3) See "Methods of Forecasting Container Handling Volume", Peng Hong, People's Press of Communication, 1999 
value ${ }^{4)}$. If this distance is reflected on the output variable, it will correspond to the simultaneous actual output quantity and the disparity between the effective value and the actual output quantity.

This kind of distance is defined as Closeness. Closeness between the two values can be described in various mathematical ways. For example, Closeness between the two positive numbers $a_{1}$ and $a_{2}$ can be described as:

$$
\begin{aligned}
& \delta_{\alpha 1 \alpha^{2}}=/ \alpha_{1} \quad \alpha_{2} / \text { or } \\
& \delta_{\alpha_{1} \alpha_{2}}=\frac{\alpha_{1}-\alpha_{2}}{\sqrt{\alpha_{1} \alpha_{2}}} \quad \text { or } \quad \delta_{\alpha_{1} \alpha_{2}}=\frac{\alpha_{1}-\alpha_{2}}{\alpha_{1}}
\end{aligned}
$$

The above-defined Closeness is virtually another dimension information about the forecast variable, and a constant description of the Closeness will reflect the development information on the forecast variable.

The constant temporal forecast variable and its Closeness between every moment's effective value can be applied to figure out the additional compensation need for the static causality forecast result. The method goes like this: first, on the basis of observation time, a mean value of Closeness is achieved by various means to reflect the "average" behavioral model on the observation time system. Then, the Closeness margin arising from the forecast time is to be used to reflect the dynamic development on forecast span system. At last, this margin can be conversed into the additional dynamic compensation value.(The Method of DCV calculation)

If this dynamic forecast method is employed, the solution to the effective value will be critical. Here we adopt the Data Envelopment Analysis (DEA) to work out the effective value.

\subsection{Solution to the Effective Value}

DEA is a new linear program developed from the concept of relative efficiency evaluation. Several up-to-par or approximately up-to-par production systems on the base of most favorable model are chosen as a decision-making unit of horizontal comparison to evaluate the DEA with the involvement of forecast system and the unit. Suppose there are $n$ units, $m$ inputs, and $s$ outputs. If the forecast system is ineffective as opposed to the DEA, then the controllable projection model is to be used to get the projection. And output of the projection will be the effective value in this article. The controllable projection model goes like this:

$$
\min \left\{\sum_{i=1}^{m} p_{i} \alpha_{i}-\sum_{r=1}^{s} q_{r} \beta_{r}\right\}
$$

$$
\begin{array}{ll} 
& \sum_{j=1}^{n} \lambda_{j} x_{i j} \leq \alpha_{i} x_{i j 0} \\
& \sum_{j=1}^{n} \lambda_{j} y_{i j} \geq \beta_{r} y_{i j 0} \quad j=1,2, \ldots, n \\
& \lambda_{j} \geq 0 \quad j=\{1,2, \ldots, m\} \\
& i \in I I=\{\quad R=\{1,2, \ldots, m\} \\
& r \in R
\end{array}
$$

$\mathrm{p}_{i}$ and $\mathrm{q}_{\mathrm{r}}$ are weighted parameters, and generally we can choose the relative weight of input index and output index.

By controlling $\alpha$ and $\beta$ to form various restriction, we can get the projection that meets our demand and aim. In this article, we hope to obtain the projection when the input is stable, so we can order

Then, the model can be simplified as:

$$
\begin{aligned}
& s . t \quad \min \left\{m-\sum_{i=1}^{m} \beta_{r}\right\} \\
& \sum_{j=1}^{n} \lambda_{j} x_{i j} \leq x_{i j 0} \\
& \sum_{j=1}^{n} \lambda_{j} y_{i j} \geq \beta_{r} y_{i j 0} \\
& \lambda_{j} \geq 0 \quad i \in I \quad r \in R \quad j=1,2, \ldots, n
\end{aligned}
$$

\subsection{The Dynamic Compensation Model}

A constant effective value out of the forecast variable on the observation time makes it possible to obtain a constant Closeness Value between the observation value and the effect value on the Forecast Value. On such a base, forecast can be actualized.

Firstly, the Causality Forecast Model is employed (the Structural Neutral Network Forecast Model is used in this article) used to obtain the static forecast result of the Forecast Variable. Then, the following dynamic compensation model is employed to obtain the additional dynamic compensation value.

The constant Closeness concluded from the Observation Time can function as a regression curve fit. For example, the function equation of the fit curve concluded goes something like this:

$$
\delta=\delta(t) \quad t \in\left[t_{1}, t_{m}\right]
$$

$\left[t_{l}, t_{m}\right]$ is the observation time. If a conspicuous rising tendency is shown on the curve, the Closeness Forecast

4) Sun Chuqiao, Han Wenxiu, A Forecast Method Research into the Dynamic Economic System, Theory and Practice on the Sytem Project Journal, 1992(2), p.59 


\section{A Study of Dynamic Forecast on Port Container Handling Capacity}

Value on the Forecast Time can be obtained by out-pushing the curve directly. Otherwise, the Time Series Forecast Methods alike can be used to get the Closeness Forecast Value.

If Closeness is defined with distance, that

is: $\delta_{a_{1} \alpha_{2}}=\left|\begin{array}{ll}a_{1} & \alpha_{2}\end{array}\right|$

then the additional dynamic compensation value will be Formula 1:

$$
\Delta y \Sigma\left(t_{m+s}\right)=\frac{\int_{t_{1}}^{t_{m}} \delta(t) d t}{t_{m}-t_{1}}-\delta\left(t_{m+s}\right)
$$

$y$ stands for the forecast variable, $\delta\left(t_{m+s}\right)$ can be the time order forecast result. The terminal forecast result is Formula 2:

$$
y \sum\left(t_{m+s}\right)=y\left(t_{m+s}\right)+\Delta y \Sigma\left(t_{m+s}\right)
$$

Here, $y\left(t_{m+s}\right)$ stands for the static forecast result.

With the variation of the Closeness definition, the form of the additional compensation value will be different.

\section{The Dynamic Forecast of $\mathrm{CHC}$ of Shanghai port}

We can first use the Structural Network Forecast Model to predicate the static value of CHC of Shanghai Port. In this article, the author uses the BP Network, whose structure consists of three layers, namely $n-n_{I}-1$ network: $n$ stands for the input node number, $n_{1}$ the middle implicit node number, and 1 the output node number. In this article, the CHC data of Shanghai Port from 1992 to 1999 is used as the input normal sample matrix; the CHC of Shanghai Port from 1991 to 1998 as the first row of the input array matrix; the Shanghai foreign import-export volume from 1991 to 1998 and from 1992 to 1999 respectively as the second and the third row; the domestic gross product of Shanghai from 1991 to 1998 and from 1992 to 1999 respectively as the fourth and the fifth row of the input array matrix which is used to fit the $\mathrm{CHC}$ of Shanghai Port, and to establish the connection weighted value and the threshold value between the each layer.

The algorithm employed here is the utmost decline method. In view of the fact that there are minimum part, overdue slowness of the constringency speed of the leaming algorithm, and even occasional torpidity appearing in the BP neutral network, we can alter the step, add the inertia momentum or dynamically adjust the step and the inertia momentum to achieve a remarkable fit accuracy. The maximum relative error should not exceed 3\%.

After fitting, we can forecast Shanghai Port $\mathrm{CHC}$ in the next five years; thus we can get an input array matrix consisting of five lines and five rows. The first row consists of the previous year's CHC of the forecasting year; the second row consists of the previous year's foreign importexport volume of the forecasting year; the third row consists of the same year's foreign import-export volume of the forecasting year; the fourth row consists of the previous year's domestic GDP of the forecasting year; the fifth row consists of the same year's domestic GDP of the forecasting year. And each line consists of the same and the previous year's corresponding economic quota of the forecasting year.

The problem to be solved is all the other elements are unknown numbers before forecasting except the first element in the first row of the matrix, so in this article, the author adopts the first line to forecast the $\mathrm{CHC}$ in 2000 . Then, put this data into the blank position of the second line of the first row so as to get the $\mathrm{CHC}$ in 2001. Accordingly, the $\mathrm{CHC}$ in 2002,2003 , and 2004 can be figured out in this way. The result is shown in Table 1.

After figuring out the static value of Shanghai $\mathrm{CHC}$, we can set off to work out the dynamic compensation value of it. In this article, Hong Kong and Singapore are chosen as the decision-making unit of the horizontal comparison ${ }^{5}$, GDP and foreign import-export volume chosen as input ${ }^{6}$, and the CHC chosen as output; the observation time is from 1991 to 1998. The above controllable projection model can be used to work out the effective value from 1991 to 1998.

Table 1 The CHC of Shanghai port by using the SNN $(10,000$ TEU)

\begin{tabular}{|c|c|}
\hline Year & CHC(a) \\
\hline 2000 & 473.0 \\
\hline 2001 & 571.5 \\
\hline 2002 & 671.3 \\
\hline 2003 & 778.7 \\
\hline 2004 & 876.3 \\
\hline
\end{tabular}

4) Sun Chuqiao, Han Wenxiu, A Forecast Method Research into the Dynamic Economic System, Theory and Practice on the Sytem Project Journal, 1992(2), p.59

5) Hong Kong and Singapore here are regarded as the most favorable models in terms of CHC.

6) Although there are other factors are chosen as variables for the $\mathrm{CHC}$, GDP and international trade volume are most widely used as variables for $\mathrm{CHC}$ forcasting and are regarded as most sensitive to $\mathrm{CHC}$ variation 
Closeness in this article is defined as Formula 3:

$\delta_{\beta_{\alpha}}=\frac{\beta-\alpha}{\beta}$

here $\alpha$ stands for the observation value of the $\mathrm{CHC}$, while $\beta$ the effective value. The above controllable projection model can be used to work out the effective value from 1991 to 1998 .

The result is shown as following Table 2.

The closeness sequence frome 1991 to 1998 can be used to form a curve by least square method(1sm), and it supposed as: $\delta(t)=\alpha e^{-b t}$

We can get the following fit curve equation after calculation: $\delta(t)=e^{241.668-0.1033 t}$

If we out-pushing this curve, we can obtain the closeness value of year 2000-2004 as following:

$$
\begin{aligned}
& \delta\left(t_{2000}\right)=0.1782, \delta\left(t_{2001}\right)=0.1599 \\
& \delta\left(t_{2002}\right)=0.1499, \delta\left(t_{2003}\right)=0.1307 \\
& \delta\left(t_{2004}\right)=0.1179
\end{aligned}
$$

According to Formula 1, we can calculate $\Delta y \sum\left(t_{m+s}\right)$, they are

$$
\begin{aligned}
& \Delta \delta_{2000}=0.1418, \Delta \delta_{2001}=0.1592 \\
& \Delta \delta_{2002}=0.1748, \Delta \delta_{2003}=0.1889 \\
& \Delta \delta_{2004}=0.2016 .
\end{aligned}
$$

According Formula 3, the definition of Closeness, we can convert to following fromula:

The DCV of year $\mathrm{j}$ /(The Causualitiy Forecast Value of year $j+$ The DCV of year $j)=\Delta \delta$;

So, The DCV of year $\mathrm{j}=$ (The Causality Forecast Value of year $\mathbf{j}) * \Delta \delta_{j} /\left(1-\Delta \delta_{j}\right)$ (4)According to Formula 4 , we can get the following table

Table 2 The Effective Value of $\mathrm{CHC}$ of Shanghai From 1991 to 1998

\begin{tabular}{|c|c|c|c|}
\hline Year & $\begin{array}{c}\text { Effective } \\
\text { value }(\beta)\end{array}$ & $\begin{array}{c}\text { Real } \\
\text { value }(\alpha)\end{array}$ & $\begin{array}{c}\text { Closeness } \\
\delta_{\beta \alpha}\end{array}$ \\
\hline 1991 & 99.7 & 57.7 & 0.4213 \\
\hline 1992 & 123.6 & 73.1 & 0.4086 \\
\hline 1993 & 148.6 & 93.5 & 0.3708 \\
\hline 1994 & 185.15 & 120.0 & 0.3519 \\
\hline 1995 & 218.87 & 152.7 & 0.3023 \\
\hline 1996 & 266.02 & 197.2 & 0.2587 \\
\hline 1997 & 315.34 & 253.7 & 0.1955 \\
\hline 1998 & 401.19 & 306.6 & 0.2358 \\
\hline
\end{tabular}

Table 3 The DCV of $\mathrm{CHC}$ of Shanghai Port from 2000 to 2004

\begin{tabular}{|c|c|}
\hline Year & DCV $(10,000)(\mathrm{b})$ \\
\hline 2000 & 78.1 \\
\hline 2001 & 108.2 \\
\hline 2002 & 142.2 \\
\hline 2003 & 181.3 \\
\hline 2004 & 220.8 \\
\hline
\end{tabular}

By adding the above data(Tale 3, DCV) and the result of the neutral network(Table 1 , the static forecast result), we can get the terminal forecast result of $\mathrm{CHC}$ of Shanghai Port. We list the data in Table 47 ).

Table 4 The Dynamic Forecast Result of $\mathrm{CHC}$ of Shanghai Port from 2000 to 2004

\begin{tabular}{|c|c|}
\hline Year & CHC(10,000 TEU) \\
\hline 2000 & 551.1 \\
\hline 2001 & 679.7 \\
\hline 2002 & 813.5 \\
\hline 2003 & 960.0 \\
\hline 2004 & 1079.1 \\
\hline
\end{tabular}

\section{Data Analysis}

From the above forecast data, the figure is bigger than most other forecast results of $\mathrm{CHC}$ of Shanghai Port. But with a careful analysis of the data, we find that the average growth rate $18.82 \%$ from 2001 to 2004 doesn't show a conspicuous increase compared with the several previous years' high-speed increase. Furthermore, when compared with the CHC of Singapore and Hong Kong, the case in Shanghai from 2000 to 2004 shares a similarity with the case in Singapore and Hong Kong from 1990 to 1994. The gap between them is ten years, and we are confident of Shanghai keeping up with the pace Hong Kong and Singapore performed from 1999 to 1994.

In the next few years, Shanghai will enjoy a rapid increase of $\mathrm{CHC}$ for the following reasons: Shanghai itself is generating more containers; Shanghai is a place in which the generative productions of international containers are to be transferred from such provinces as Sichuan, Jiangxi, and Anhui situated at the middle or upper reach of Yangtze

7) According to Formula 2. 


\section{A Study of Dynamic Forecast on Port Container Handling Capacity}

River; the further economic development of Midwest will make more goods transferred in Shanghai; what is more, with the construction and development of Shanghai being the international shipping center (ISC), the international ocean containers transferred by the Asia main lines will be on a constant decline, but containers transferred in Shanghai Port will be increasing. So, in the next few years, with a prospect of $9 \%$ 10\% economic growth and 13\% foreign import-export increase, there is every possibility for Shanghai Port to have a $19 \%$ average annual increase of $\mathrm{CHC}$.

On the other hand, we also should keep a sober mind that with the emergence of mega container ships, if Shanghai can't grasp the present foundation to exploit the potentials and can't construct deep-water ports quickly, it will be difficult for Shanghai to have a further high-speed increase of $\mathrm{CHC}$, and it will delay the process of Shanghai to be the international shipping center.

\section{Conclusion}

In this article, the author proposes a dynamic forecast method for the CHC of Shanghai Port, which alters the usual method of behavioral model to forecast the $\mathrm{CHC}$. By this method, we found the actual $\mathrm{CHC}$ in 2000 was in accordance with our forecast, and we believe such a forecast is still an ideal method in the next few years.

The causality of $\mathrm{CHC}$ is complicated. Here, the author makes an attempt to analyze it with the GDP and foreign import-export as its variables, but introduction of the other variables needs further research. The method used in this article, is a newer forecast method for predicating CHC, which is virtually a combination of qualitative and quantitative analysis, which plays a significant role in the $\mathrm{CHC}$ forecast.

\section{Reference}

[1] Shen Zhaohan, Zhu Qiao, Guan Guangmou, $D E A$ Theory, Method and Application, Beijing, Science Publishing House, 1999.

[2] Sun Chuqiao, Han Wenxiu, A Forecast Method Research into the Dynamic Economic System, Theory and Practice on the System Project Journal, 1992(2).

[3] Wu Yuhua, General Projection Research into DEA Model, System Project Journal, 1996(4).

[4] Pei Shuhong, Generative Production Research on the Containers of Shanghai International Shipping Center, [Thesis for Master Degree], Shanghai Maritime University.

[5] Jiao Licheng, Theory of the Neural Network System, Xian Electronic Science and Technology Publishing House, 1997.

원고접수일 : 2002년 02월 20일

원고채택일 : 2002년 04월 30일 